\title{
Improvements to the Heat Transfer Process on a Hydrogen Sulphide Gas Coolers System
}

\author{
Andres A. Sánchez-Escalona ${ }^{1 *}$, Ever Góngora-Leyva² \\ ${ }^{1}$ Metallurgical Mining Higher Institute, Electromechanical Master's Program, 83-330 Moa, Holguín, Cuba \\ ${ }^{2}$ Metallurgical Mining Higher Institute, Faculty of Metallurgy and Electromechanical, 83-330 Moa, Holguín, Cuba
}

Corresponding Author Email: sanchezescalona88@gmail.com

https://doi.org/10.18280/ijht.370130

Received: 10 August 2018

Accepted: 12 March 2019

\section{Keywords:}

hydrogen sulphide, jacketed, modeling, shell-and-tube heat exchanger, thermal analysis

\begin{abstract}
To operate the hydrogen sulphide gas coolers outside design parameters impacts the production process, because the resulting increased gas outlet temperature and lower sulphur separation effectiveness, which favors pipe plugging and damage to down-stream compressors. A procedure was formulated for thermal analysis of jacketed shell-and-tube heat exchangers, in order to examine the object of study and propose improvements to existing facilities. Beyond conventional analysis, this work included the experimental method as well as mathematical modeling, that were not interrelated in previous researches. A cooling system that meets current technological requirements was identified, consisting of two sets of four improved coolers, where each set operates at a maximum hydrogen sulphide flowrate of $5.565 \mathrm{~kg} / \mathrm{s}$ and $7.500 \mathrm{~kg} / \mathrm{s}$ of water feeding each exchanger, thus reaching a gas cooling rate below $313 \mathrm{~K}$.
\end{abstract}

\section{INTRODUCTION}

Hydrogen sulphide $\left(\mathrm{H}_{2} \mathrm{~S}\right)$ is a flammable and harmful gas, necessary to make mercaptans, several chemical compounds and for mining and metallurgy applications. It is used in catalyst activation and poisoning, treatment of metallic surfaces, production of heavy water for the nuclear industry, as well as purification of nickel, manganese, hydrochloric and sulphuric acid [1].

The commercial way to produce high-purity hydrogen sulphide is by reacting hydrogen with molten sulphur at elevated temperatures, inside a reactor and its quench tower. Downstream, in a set of jacketed shell-and-tube heat exchangers, the resulting gas is cooled down from $416.15 \mathrm{~K}$ to $310.15 \mathrm{~K}$. In addition, the remaining sulphur carried over by stream is removed within these exchangers.

This research was carried out in an online set of hydrogen sulphide gas coolers, which has indicated to be operating with the following problems:

- Increased gas flowrate through the heat exchangers due to the higher production targets.

- Higher than design hydrogen sulphide exit temperature.

- Increased sulphur carryovers, therefore causing valve and pipe plugging, as well as damage to down-stream equipment.

- Reduced useful life of heat exchangers and increased compressors maintenance costs.

- Sulphur spillage during pipe, valve and other equipment repairs, or pressure vessels purge.

There is not a specific procedure at the plant site for the thermal analysis of jacketed shell-and-tube heat exchangers. Thus, the assessment of the hydrogen sulphide gas coolers has been carried out without considering the shellside-tojacket heat transfer, using conventional methods: Logarithmic Mean Temperature Difference (LMTD) and Effectiveness-Number of Transfer Units ( $\varepsilon-N T U)$ [2-4].
There are limitations when using such methods for the study of three-fluid equipment, since the equations and charts to determine the LMTD correction factor and the $\varepsilon$-NUT diagrams are not available for complex heat exchangers [5]. On the other hand, original design parameters were used for the calculations, without including the fact that the plant operating conditions have changed. As the experimental method was not applied, reference values were assumed for the overall heat transfer coefficients and fouling factors [2-3, 6], leading to incorrect equipment sizing.

Despite the rating and thermal design theory of three-fluid heat exchangers has been formulated, references regarding the study of jacketed shell-and-tube devices were not found in consulted literature. Our review suggests that tripleconcentric-tube is the most studied configuration, as they are simpler in construction and practically straight-forward to evaluate [7-11]. Sekulić \& Shah offered a detailed review on thermal design theory of three-fluid heat exchangers [12], although stating that shell-and-tube multi-fluid equipment has complex stream arrangements, which usually cannot be classified within the parallel or cross-flow configurations discussed by them. The paper illustrates a few shell-and-tubetype heat exchangers, none of them of the jacketed kind. Moreover, shell-and-double concentric-tube heat exchanger were investigated by Bougriou \& Baadache [13], Abdulmajeed \& Allawi [14] and Shahril et al. [15], but the appraised prototypes represent a concept not developed yet enough for industrial applications. Its configuration makes maintenance and tubes cleaning very impractical.

Taking the existing research gaps into consideration, the aim of this paper is to establish a procedure for thermal analysis of jacketed shell-and-tube heat exchangers, in order to thoroughly examine the hydrogen sulphide cooling system and propose improvements to existing facilities. It would allow meeting technological requirements under the plant current exploitation conditions. 


\section{THERMAL ANALYSIS PROCEDURE}

The procedure for thermal analysis of jacketed shell-andtube heat exchangers was proposed for three successive stages (Figure 1):

1. Evaluation of the heat exchangers under current operating conditions. The initial data is gathered by applying the experimental method, measuring key variables related to the heat exchange process. The flowrate and temperature variations influence in performance of the facility is determined. In addition, the overall heat transfer coefficients and actual fouling thermal resistances are calculated.

2. Evaluation of the existing heat exchangers design. This step is carried out after confirming that expected performance of the system cannot be attained. The goal is to identify constructive and operational aspects that can be improved, without considerably increasing the heat exchangers size or the number of series-installed units.

3. Simulation of alternative hydrogen sulphide cooling systems. Lastly, simulation is performed using mathematical modeling of the heat exchangers. In this step, fouling thermal resistances calculated from experimental data (first stage) and suggested design improvements (second stage) are taken into account. The challenge is to propose a heat exchangers system able to meet current process requirements.

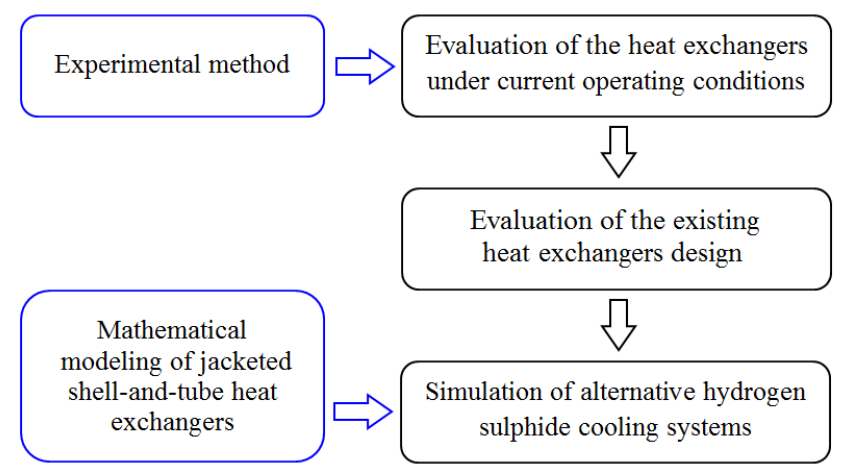

Figure 1. Proposed procedure logical sequence

Following assumptions were made in order to simplify calculations and the experimental technique, as their influence on the accuracy of applied methods is not relevant:

- Heat exchangers operate under steady-state conditions.

- The overall heat transfer coefficients are constant throughout the heat exchangers.

- The specific heats of each fluid are also constant throughout the heat exchangers.

- Heat transfer to or from the surroundings is negligible.

- Potential and kinetic energy variations are negligible.

- Longitudinal heat conduction in the fluids and the walls are negligible.

- The temperature on each fluid is uniform over every flow cross section.

- There are no phase changes.

- Walls and fouling thermal resistances are distributed uniformly across the exchanger.

- The hydrogen sulfide flowrate is constant for every operating shift.

- Water flowrate measurements (for the tubeside and the jacket-side) were taken in common pipe branches, so half of the flow is assumed for each heat exchanger supposing that the pressure drops across them are similar, as they have equal configuration and dimensions.
Despite common references [2-3, 12] did not make an assessment of the idealizations incorporated in heat exchanger basic design theory, Peigné et al. [10] reported heat transfer rates relative differences lower than 5\% when comparing experimental and numerical results. The influence of previous-mentioned simplifications on current research is further discussed (refer to section 3.3).

\subsection{System description and experimental setup}

The studied system consists of four jacketed shell-and-tube heat exchangers. Each pair (two coolers in series) was designed to transfer $138 \mathrm{~kW}$ of heat, through an area of $49.2 \mathrm{~m}^{2}$. The hydrogen sulphide gas flows on the shellside, in a single pass, while the water circulates at the tubeside, in four passes, as well as through the external jacket (Figure 2). Every pair of heat exchangers operates for eight hours in gas cooling service, and later they are switched over to supply steam (at the tubeside and the jacket-side) for four or six hours to remove the sulphur scale from inside the equipment. While one pair operates in the cooling cycle, the other runs in sulphur drainage service, and vice versa.

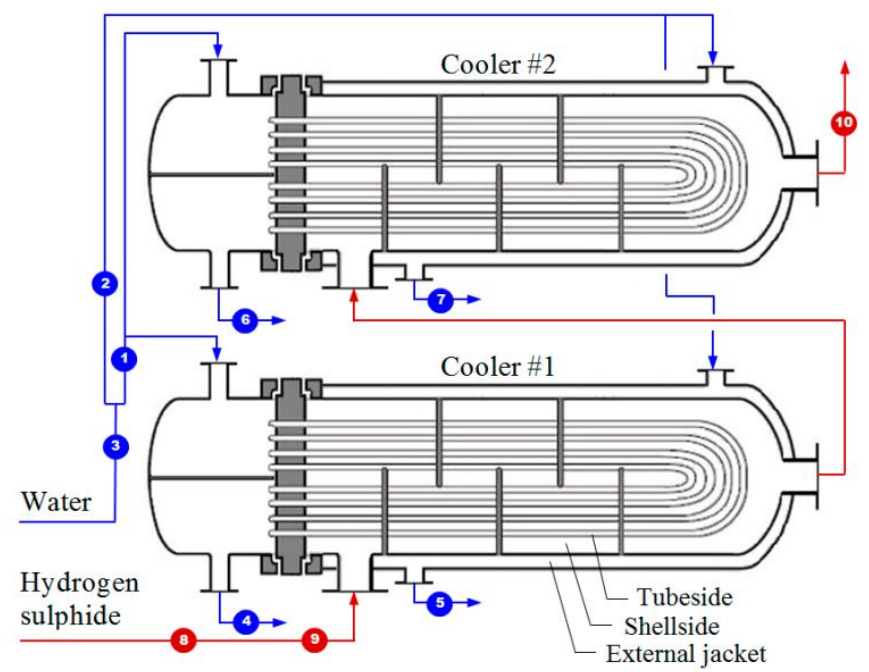

Figure 2. Hydrogen sulphide gas coolers pair and measuring points

The passive experimentation method was applied, due to the uninterrupted production philosophy of the plant. This approach is also known as nonexperimental research, since the researchers do not attempt to control or manipulate the independent variables. Instead, control was exerted over levels of those parameters related with the thermal exchange process under study [16-17].

Recorded parameters are listed below (measuring points according to Figure 2).

Water:

1. tubeside flowrate;

2. jacket-side flowrate;

3. inlet temperature;

4. cooler \#1 tubeside outlet temperature;

5. cooler \#1 jacket-side outlet temperature;

6. cooler \#2 tubeside outlet temperature;

7. cooler \#2 jacket-side outlet temperature.

Hydrogen sulphide:

8. mass flowrate;

9. cooler \#1 inlet temperature;

10. cooler \#2 outlet temperature. 
The instrumentation and their technical characteristics are:

- Temperatures: industrial thermowells and Ashcroft bimetallic thermometers, $0.1 \mathrm{~K}$ measurement precision;

- Water flowrate: Proline Prosonic Flow 93T portable flowmeter, $6.3 \cdot 10^{-6} \mathrm{~m}^{3} / \mathrm{s}$ measurement precision;

- Hydrogen sulphide flowrate: process signal to a Siemens S7-400 PLC and Citect SCADA 7.10 system, $10^{-4} \mathrm{~kg} / \mathrm{s}$ measurement precision.

Three experimental observations were performed for eight hours on alternate days, after starting the same pair of heat exchangers in the cooling service. During each cycle, twenty measurements of process parameters were recorded. Three repetitions for each measurement were made, to reduce the occurrence of random and accidental errors of observation. The cooler \#1 gas outlet temperature was determined by means of an energy balance, while the cooler \#2 outlet temperature was validated in the same way [10].

\subsection{Evaluation of the heat exchangers under current operating conditions}

Fundamental equations for heat exchangers rating and design were used to assess performance of studied coolers, including concepts that are inherent to the analysis of threefluid equipment (Figure 3). Since two major thermal communications are present, two overall heat transfer coefficients have to be determined: one related to the internal heat exchange, between the tubeside and the shellside fluid; while the other is associated to the external exchange, between the shellside and the jacket fluid. Consequently, separate values of fouling thermal resistances are calculated for each thermal communication surface [2-3, 10-12].

\subsection{Evaluation of the existing heat exchangers design}

The studied hydrogen sulphide gas coolers design is about 60 years old. During this period, calculation methods and tools as well as construction materials and technologies have evolved significantly [18]. That is why an updated evaluation of the existing equipment design is carried out, taking the following into consideration: heads type, tube bundle configuration, shell type, correct fluid placement, baffle spacing, baffle cut, tube layout pattern, tube pitch, tube diameter, fluids velocity and flow regime, use of multiple shells, flow arrangement, enhanced heat transfer, among others. Parameters to be improved are identified during the analysis, if deviations are found when compared to optimal design practices like those recommended by Mukherjee [19], Kumar-Singh [20], Bhattacharyya \& Mukherjee [21], and Shukla et al. [22].

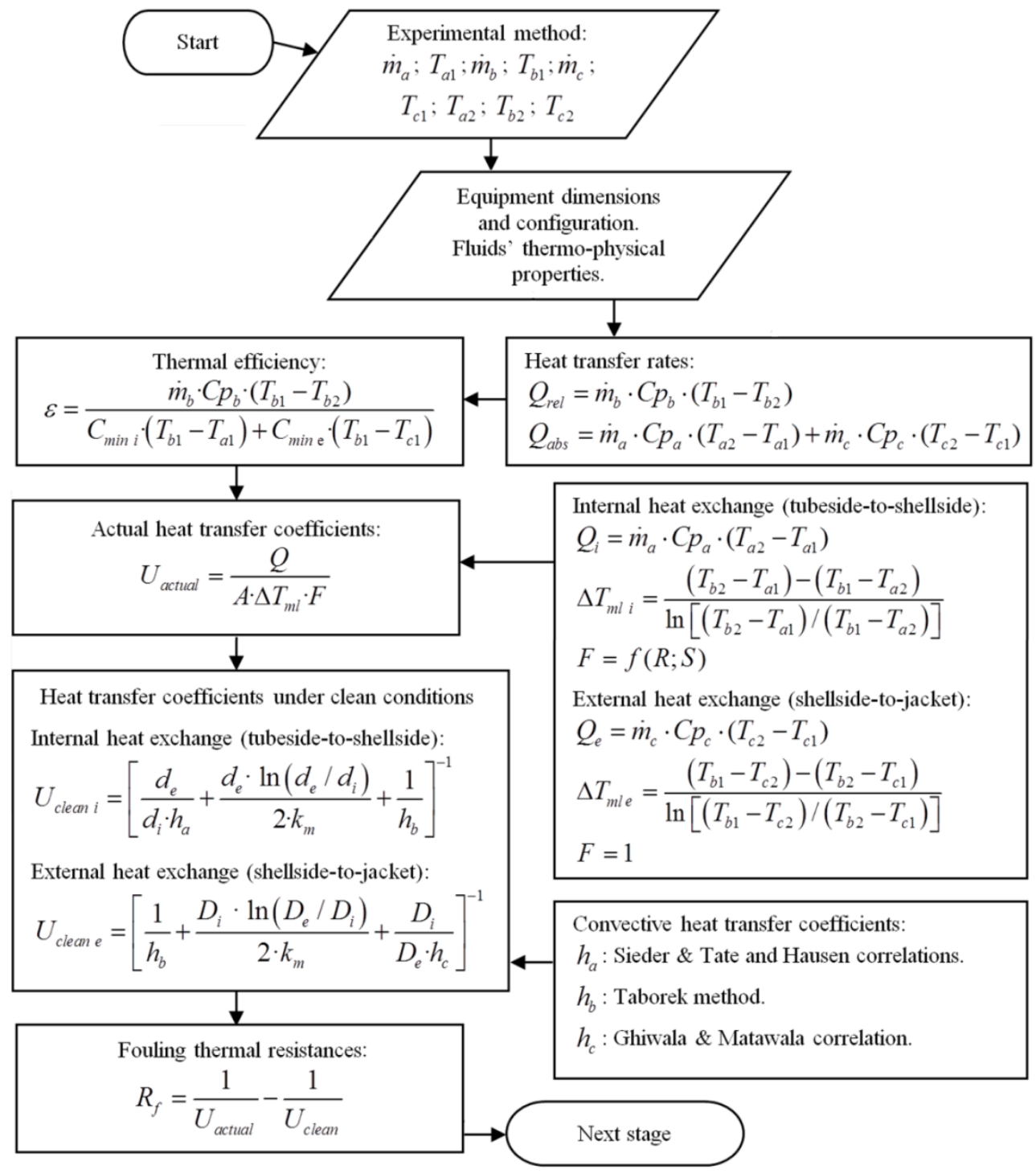

Figure 3. Calculation procedure flowchart 


\subsection{Mathematical modeling of jacketed shell-and-tube heat exchangers}

A model was proposed to simulate the performance of jacketed shell-and-tube heat exchangers, with all streams in single-pass counter-current flow (Figure 4). On the scheme, the central pipe surface is equivalent to the total tubes heat transfer area.

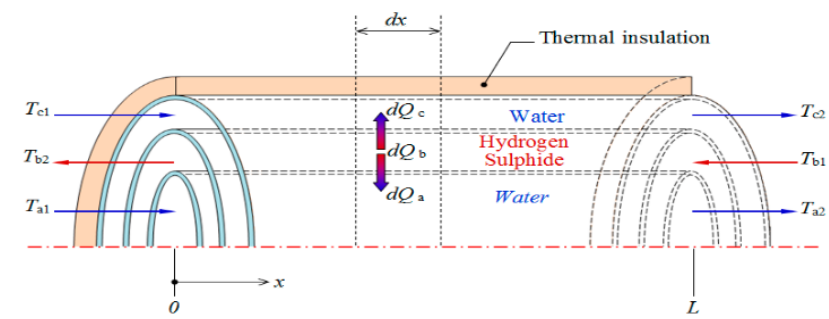

Figure 4. Physical model scheme
In present study, the water circulates on the tubeside, represented by the model central pipe, and also through the jacket, represented by the outer annular space. The hydrogen sulphide gas flows on the shellside, represented by the inner annular space, counter-current to both water streams. During the heat exchange process, hydrogen sulphide is cooled down, while water is heated up. Thermal insulation avoids heat transfer to the surroundings.

The model governing equations allows prediction of exit temperatures for all three streams and plotting of temperatures distribution along the heat exchanger (Figure 5). The set of second order homogeneous ordinary differential equations (ODE), with constant coefficients, has analytical solution. Since the discriminant of the characteristic equation is positive, the ODE system roots $\left(r_{1}\right.$ and $\left.r_{2}\right)$ are real and different. The constants of the $\operatorname{ODE}$ system $\left(G_{1}\right.$ to $\left.G_{4}\right)$ are determined from the roots and boundary conditions, solving two systems of linear equations with two variables [9]

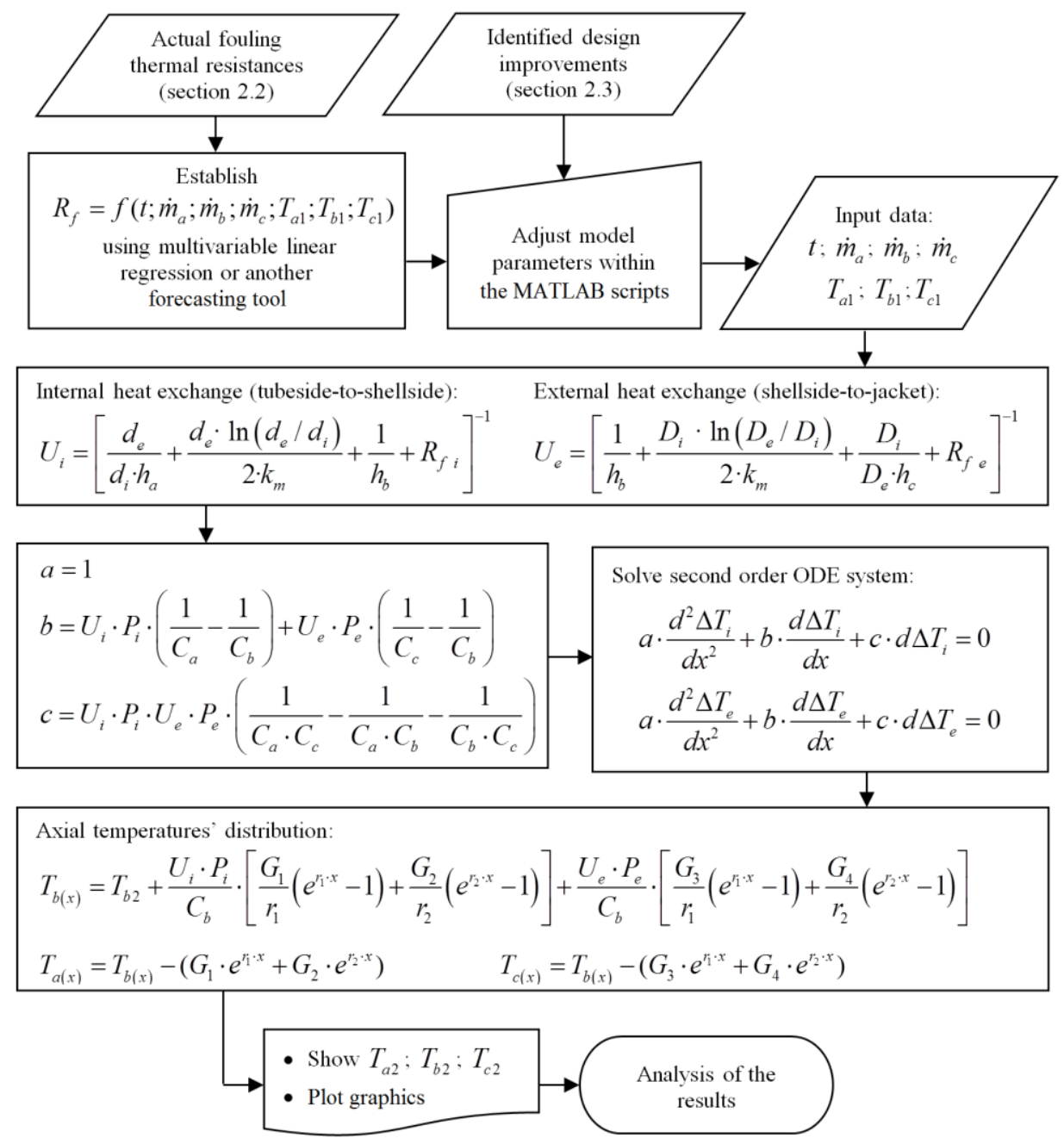

Figure 5. Modeling stage flowchart

The model described herein starts from the theory developed by Unal [7] and Batmaz \& Sandeep [9], although applying a different methodology for calculation of the overall heat transfer coefficients. On the present research these coefficients were determined analytically, using the Taborek method for approximation of the shellside local heat transfer coefficient and using multivariable regression techniques to estimate actual fouling thermal resistances.

On previous studies, for counter-current flow arrangements, the boundary conditions were defined considering the fluid outlet temperature through the inner annulus as input data, which is not practical on industrial applications modeling because the fluid exit temperatures are typically the unknowns. To overcome this issue, and only having the inlet conditions as input variables, an iteration routine was incorporated to the jacketed shell-and-tube heat exchangers simulation script. 


\subsection{Simulation of alternative hydrogen sulphide cooling systems}

Simulation of alternative facilities consists of using the proposed mathematical model to evaluate the performance of different hydrogen sulphide cooling systems, which should be capable of reaching an adequate process fluid outlet temperature, as well as meeting other technological requirements (for this case, it is required to improve the sulphur separation effectiveness inside the heat exchangers). Current operating conditions parameters are used as input data, although the system response could be analyzed for other ranges of independent variables.

The identification of an alternative hydrogen sulphide cooling facility able to achieve the necessary heat exchange may require a trial and error process, but this inconvenience is also inherent to other contemporary modeling and simulation techniques, such as the artificial neural networks [23]. Although the primary factors in deciding which variant to implement will be the heat transfer analysis and costs, other aspects to be considered are: weight, size, fouling rate, cleaning procedure, safety, operational and maintenance requirements, as well as useful life [2, 24].

\section{RESULTS AND DISCUSSION}

\subsection{Evaluation of the heat exchangers under current operating conditions}

It was confirmed through the experimental method that the studied heat exchangers do not meet the expected performance under actual exploitation conditions:

- The hydrogen sulphide outlet temperature for the heat exchangers set was from $11.85 \mathrm{~K}$ to $49.65 \mathrm{~K}$ higher than targeted design temperature $(310.15 \mathrm{~K})$.

- Water flowrate supplied to the heat exchangers represented $53.5 \%$ to $56.6 \%$ of the design value $(2.974 \mathrm{~kg} / \mathrm{s})$.

- Cooler \#1 outlet water temperature exceeded $315 \mathrm{~K}$, which almost duplicates fouling on the water-side $[4,6,25]$. This trend was less noticeable in cooler \#2, where only $1.67 \%$ of the measurements exceeded such temperature.

- The water did not reach the turbulent flow, required for optimum heat transfer. Maximum Reynolds number computed for the tubeside and the jacket-side flows were 2378 and 502, respectively.

Thermal efficiency losses vary from $4.9 \%$ to $10.1 \%$, mainly caused by progressive sulphur deposition around the heat transfer surfaces due to gas pressure and temperature drops [26-27]. The buildup carried over by the process stream grows over time, creating insulation layers that reduces the overall heat transfer coefficients between 7.5 and $20.8 \mathrm{~W} /\left(\mathrm{m}^{2} \cdot \mathrm{K}\right)$

Flow velocity is one of the main variables influencing on fouling levels, as it was determined that higher hydrogen sulphide flowrates minimizes sulphur buildup inside the heat exchangers. On the other hand, higher fouling factors at the end of the cooling cycle relate to a greater removal effectiveness of the sulphur carried over by the gas.

\subsection{Evaluation of the existing heat exchangers design}

The following improvements have been identified after a thorough assessment of the coolers design:
- To reduce tube pitch from $27 \mathrm{~mm}$ to $25 \mathrm{~mm}$. TEMA [4] specifies a minimum tube pitch of 1.25 times the tube outside diameter and recommends a minimum cleaning lane of $6 \mathrm{~mm}$ between adjacent tubes. Designers prefer to use minimum tube pitch because it leads to the smallest shell diameter for a given number of tubes $[19,22]$

- To increase the number of tubes from 152 to 183 . It is achieved by reducing tube pitch, keeping the same shell diameter [6]. As a result, the heat transfer area is augmented $20.4 \%$ without changing the equipment size.

- To make water tubeside flow in single pass, thus having all streams in counter-current as it is thermally more efficient than other flow arrangements. Required area to transfer the same thermal load is smaller for this configuration [2].

- To increase the water flowrate feeding each exchanger, in order to achieve a turbulent flow [22].

Under same inlet conditions (Table 1), simulation of an improved heat exchanger -as recommended above- displays $320.74 \mathrm{~K}$ gas outlet temperature and $125.4 \mathrm{~kW}$ of heat exchange, as compared to $370.05 \mathrm{~K}$ and $66.5 \mathrm{~kW}$ for the existing equipment design (Figure 6). It corroborates that increased thermal performance can be achieved by implementing this stage of the proposed procedure.

Table 1. Process design criteria used for equipment performance evaluation

\begin{tabular}{cccc}
\hline Parameter & Tubeside & Shellside & Jacket \\
\hline Fluid & water & $\begin{array}{c}\text { hydrogen } \\
\text { sulphide }\end{array}$ & water \\
Physical state & liquid & gas & liquid \\
Mass flowrate, $\mathrm{kg} / \mathrm{s}$ & 1.487 & 1.101 & 0.565 \\
Fouling factor, $\mathrm{m}^{2} \cdot \mathrm{K} / \mathrm{W}$ & $3.50 \cdot 10^{-4}$ & $7.04 \cdot 10^{-3}$ & $3.50 \cdot 10^{-4}$ \\
Inlet temperature, $\mathrm{K}$ & 305.15 & 425.67 & 305.15 \\
Average pressure $* \mathrm{MPa}$ & 0.446 & 0.790 & 0.446 \\
Molecular weight, $\mathrm{kg} / \mathrm{kmol}$ & 18.015 & 34.081 & 18.015 \\
Density, $\mathrm{kg} / \mathrm{m}^{3}$ & 995.164 & 7.808 & 995.164 \\
Dynamic viscosity, Pa $\cdot \mathrm{s}$ & $7.66 \cdot 10^{-4}$ & $1.83 \cdot 10^{-5}$ & $7.66 \cdot 10^{-4}$ \\
Specific heat, $\mathrm{J} /(\mathrm{kg} \cdot \mathrm{K})$ & 4178.6 & 1089.0 & 4178.6 \\
Thermal conductivity, & 0.619 & 0.027 & 0.619 \\
W/(m. $\mathrm{K})$ & & & \\
\hline * Note: absolute pressure. & &
\end{tabular}

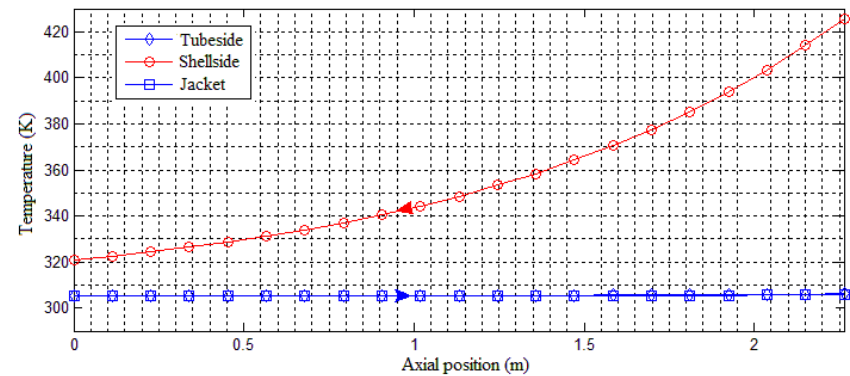

a) Heat exchanger improved design

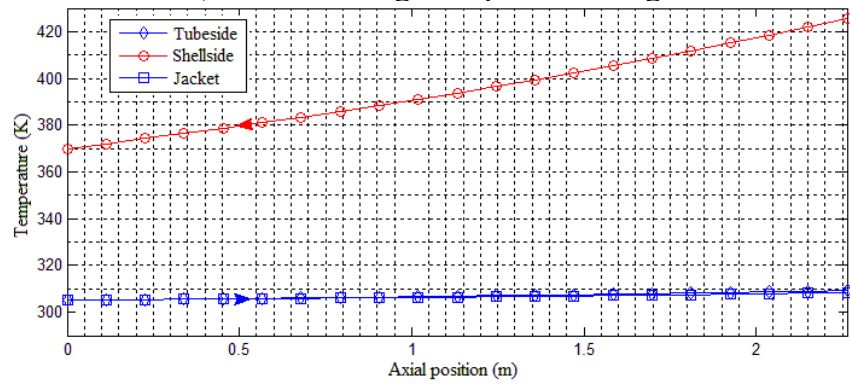

b) Heat exchanger existing design

Figure 6. Thermal performance comparison 


\subsection{Model verification}

The accuracy of the results obtained through proposed approach is considered satisfactory for the purposes of the present investigation (Figure 7).

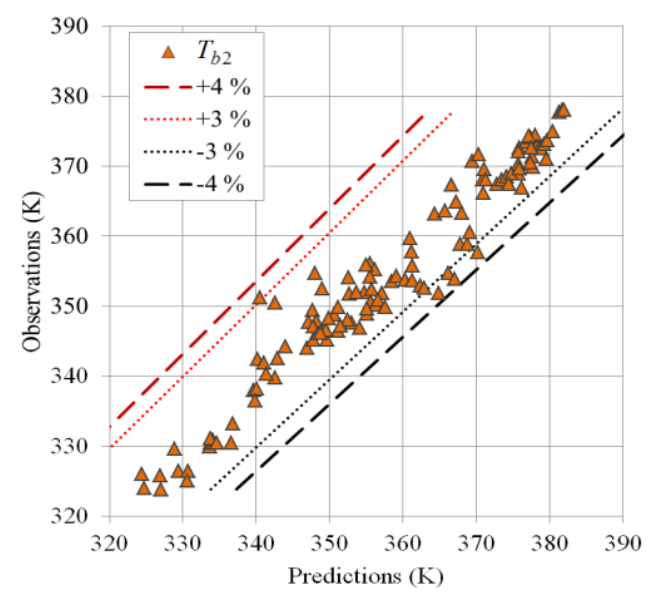

Figure 7. Model predictions vs. measured hydrogen sulphide outlet temperatures

Relative errors were lower than $4 \%$ when comparing the gas outlet temperature predicted by the model vs. the experimental measurements, for 120 data points. It is noticeable that $95.8 \%$ of these predictions did not exceed the $3 \%$ relative error. Calculated coefficient of determination $\left(R^{2}\right)$ was 0.946 .

\subsection{Simulation of alternative hydrogen sulphide cooling systems}

A system formed by two sets of gas coolers, four heat exchangers each, was analyzed. Under this configuration, each set operates in parallel with half the flowrate of produced hydrogen sulphide. Both banks have the same arrangement as the existing system, although every heat exchanger includes the improvements listed in section 3.2. The series/parallel arrangement was maintained, keeping the hydrogen sulphide stream in series across the shellside, with the cooling water flowing in parallel through the tubeside and the jackets. While two pairs of heat exchangers operate in the cooling cycle, for eight hours, the other two run in sulphur drainage cycle, and vice versa.

\subsubsection{Impact of the mass flowrates on system performance}

This system was simulated during the cooling cycle, considering that the hydrogen sulphide gas is supplied at $426 \mathrm{~K}$ and the water at $310 \mathrm{~K}$ (critical operating conditions). The model was run for a range of gas flowrates between 0.515 and $0.565 \mathrm{~kg} / \mathrm{s}$ for each set of heat exchangers, based on the plant current exploitation conditions. The range of supplied water flowrates was evaluated from 1 to $26 \mathrm{~kg} / \mathrm{s}$, and fouling thermal resistances were calculated for eight working hours. Outlet temperatures computed for the hydrogen sulphide stream exceeded the design value of $310.15 \mathrm{~K}$, with an absolute deviation that averages $3.13 \mathrm{~K}$ and varies between 2.34 and $6.89 \mathrm{~K}$ (Figure 8).

For studied ranges of the input variables, the influence of the gas flowrate variations on its outlet temperature is negligible. The exit temperature varies between $0.33 \mathrm{~K}$ and $0.94 \mathrm{~K}$ for constant water flowrates. However, the water stream has a more remarkable impact on the outlet temperature of the hydrogen sulphide. Variations between $3.62 \mathrm{~K}$ and $4.23 \mathrm{~K}$ were computed for constant gas flows. As the water flowrate increases the gas outlet temperature goes down, mainly attributed to a higher convective heat transfer coefficient resulting from changes in the tubeside flow regimen, which improves the overall heat transfer coefficient. Laminar flow was determined up to $2.4 \mathrm{~kg} / \mathrm{s}$, while the turbulent one would take place form $4.6 \mathrm{~kg} / \mathrm{s}$ on.

It was calculated that water flowrates greater than $7.5 \mathrm{~kg} / \mathrm{s}$ do not significantly reduce the temperature of the hydrogen sulphide at the outlet of the heat exchangers. Under these conditions the variations in the exit temperature remains below $0.5 \mathrm{~K}$, hence pumping more water is impractical and uneconomically justified.

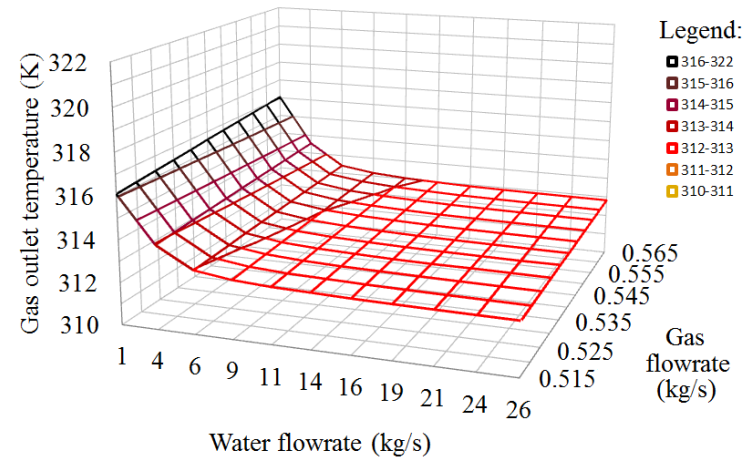

Figure 8. Impact of the mass flowrate on the hydrogen sulphide outlet temperature

3.4.2 Impact of inlet temperatures on system performance

The system performance was also simulated for fixed mass flowrates, by presetting the gas stream at $0.55 \mathrm{~kg} / \mathrm{s}$ and the water feed (to each heat exchanger) at $7.5 \mathrm{~kg} / \mathrm{s}$. The model was run for temperatures at the system inlet varying between $405 \mathrm{~K}$ and $426 \mathrm{~K}$ for the gas stream, and from $305 \mathrm{~K}$ to $310 \mathrm{~K}$ in the case of the cooling water. Both ranges cover the entire span of experimental measurements (current plant operating conditions), as well as design values. Fouling thermal resistances were estimated for eight working hours.

The water inlet temperature has a greater influence on the gas outlet temperature due to a higher heat capacity of the cold stream. A variation of $5 \mathrm{~K}$ in the water inlet changes the gas outlet temperature within the range of $4.801 \mathrm{~K}$ to $4.812 \mathrm{~K}$, while a variability of $21 \mathrm{~K}$ in the gas inlet causes fluctuations from $0.481 \mathrm{~K}$ to $0.491 \mathrm{~K}$ at the heat exchangers system outlet (Figure 9).

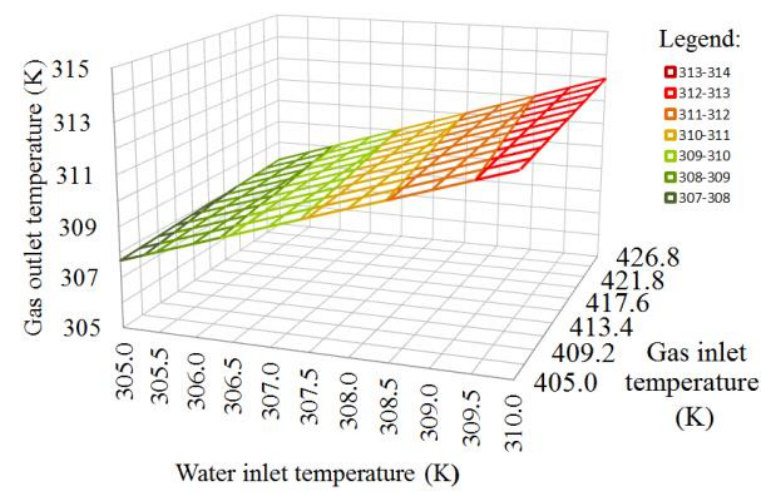

Figure 9. Impact of the inlet temperatures on the hydrogen sulphide outlet temperature 
As for the studied conditions, $47 \%$ of the values computed by the model resulted in hydrogen sulphide temperatures lower than $310.15 \mathrm{~K}$ at the outlet of the coolers system, mainly occurring when water is supplied at a temperature equal to $307 \mathrm{~K}$ or below. The remaining $53 \%$ shows deviations above design value, averaging $1.41 \mathrm{~K}$ and varying between 0.02 and $2.82 \mathrm{~K}$. This gas exit temperature increment has no significant impact on the studied hydrogen sulphide production plant.

Previous results suggest that an adequate gas temperature at the system outlet will be reached by operating two sets of improved coolers. Besides, lower fluid velocity at the shellside (half of current conditions) will increase separation effectiveness of the sulphur that is carried over by the gases inside the heat exchangers.

\section{CONCLUSIONS}

A procedure was established for thermal analysis of jacketed shell-and-tube heat exchangers, allowing a detailed evaluation of the hydrogen sulphide cooling system and defining proposals to improve existing facilities.

It was corroborated that running the hydrogen sulphide gas coolers outside design parameters impacts the production process, due to an increased gas outlet temperature from $11.85 \mathrm{~K}$ to $49.65 \mathrm{~K}$ (above required $310.15 \mathrm{~K}$ ) and lower sulphur separation effectiveness. The efficiency loss oscillated between $4.9 \%$ and $10.1 \%$, influenced by the sulphur particles carried over by the gas, whose buildup decreases the overall heat transfer coefficient within the range from 7.5 to $20.8 \mathrm{~W} /\left(\mathrm{m}^{2} \cdot \mathrm{K}\right)$.

Changes to the original heat exchangers design were suggested for improving the equipment thermal performance. When simulating actual design against the improved proposal, under the same inlet conditions, the last one reached a gas outlet temperature lower by $49.31 \mathrm{~K}$ and additional $58.9 \mathrm{~kW}$ of heat transferred.

By means of the mathematical modeling it was identified a cooling system able to achieve an adequate gas outlet temperature (below $313 \mathrm{~K}$ ) and lower sulphur carryover. It consists of two sets of four improved coolers, where each set operates at a maximum hydrogen sulphide flowrate of $5.565 \mathrm{~kg} / \mathrm{s}$ and $7.500 \mathrm{~kg} / \mathrm{s}$ of water feeding each exchanger.

\section{REFERENCES}

[1] Chou S, Ogden JM, Pohl HR, Scinicariello F, Ingerman L, Barber L, Citra M. (2016). Toxicological profile for hydrogen sulphide and carbonyl sulphide. U.S. Department of Health \& Human Services, Agency for Toxic Substances and Disease Registry. Atlanta, Georgia, USA.

[2] Kakaç S, Lui H. (2002). Heat exchangers. Selection, rating and thermal design. 2ed. CRC Press, New York, USA.

[3] Serth RW, Lestina TG (2014). Process heat transfer: principles, applications and rules of thumb. 2ed. Elseiver Academic Press, San Diego, USA.

[4] Harrison J. (editor). (2007). Standards of the Tubular Exchanger Manufacturers Association, 9ed. TEMA Inc., New York, USA.

[5] Sheweta YK, Jagadish SB, Manjunath MB. (2014).
Analysis comparing performance of a conventional shell and tube heat exchanger using Kern, Bell and BellDelaware method. International Journal of Research in Engineering and Technology 3(3): 486-496. https://doi.org/10.15623/ijret.2014.0315093

[6] Ludwig EE. (1993). Applied process design for chemical and petrochemical plants. Vol. 3, 2ed. Gulf Publishing Company, Houston, Texas, USA.

[7] Unal A. (1998). Theoretical analysis of triple concentric-tube heat exchanger. Part 1: Mathematical modeling. International Communications in Heat and Mass $\quad$ Transfer 25(7): 949-958. https://doi.org/10.1016/s0735-1933(98)00086-4

[8] Unal A. (2001). Theoretical analysis of triple concentric-tube heat exchanger. Part 2: Case studies. International Communications in Heat and Mass Transfer 28(2): 243-256. https://doi.org/10.1016/S07351933(01)00231-7

[9] Batmaz E., Sandeep KP. (2005). Calculation of overall heat transfer coefficients in a triple tube heat exchanger. Heat and Mass Transfer 41(3): 271-279. https://doi.org/10.1007/s00231-004-0546-0

[10] Peigné P, Inard C, Druette L. (2013). Ventilation heat recovery from wood-burning domestic flues. A Theoretical Analysis Based on a Triple Concentric Tube Heat Exchanger. Energies 6(1): 351-373. https://doi.org/10.3390/en6010351

[11] Ghiwala TM, Matawala VK. (2014). Sizing of triple concentric pipe heat exchanger. International Journal of Engineering Development and Research 2(2): 16831692.

[12] Sekulić DP, Shah RH. (1995). Thermal design theory of three-fluid heat exchangers. Advances in Heat Transfer 26: 219-328. https://doi.org/10.1016/s00652717(08)70297-1

[13] Bougriou C, Baadache K. (2010). Shell-and-double concentric-tube heat exchangers. Heat Mass Transfer 46 315-322. https://doi.org/10.1007/s00231-010-0572-z

[14] Abdulmajeed BA, Allawi FA. (2015). Shell and double concentric tube heat exchanger calculations and analysis. Journal of Engineering 21(1): 62-82.

[15] Shahril SM, Quadir GA, Amin NAM, Badruddin IA. (2017). Thermo hydraulic performance analysis of a shell-and-double concentric tube heat exchanger using CFD. International Journal of Heat and Mass Transfer 105: 781-798. http://dx.doi.org/10.1016/j.ijheatmass transfer.2016.10.021

[16] Hernández-Sampieri R, Fernández-Collado C, BaptistaLucio MP. (2014). Research Metodology (in Spanish). 6ed. McGraw-Hill, Mexico D.F.

[17] Edmonds WA, Kennedy TD. (2017). An applied guide to reseacrh designs: quantitative, qualitative, and mixed methods. 2 ed. SAGE Publications, Los Angeles, USA.

[18] LePree J. (2016). New ways to deal with old heat transfer issues. Chemical Engineering 123(6): 20-23.

[19] Mukherjee R. (1998). Effectively design shell-and-tube heat exchangers. Chemical Engineering Progress, Feb: 17.

[20] Kumar-Singh S. (2015). Thermal design guidelines for optimizing shell-and-tube heat exchangers. Chemical Engineering 122(2): 54-57.

[21] Bhattacharyya S, Mukherjee S. (2016). Shell-and-tube heat exchangers: The design cycle. Chemical Engineering 123(3): 61-67. 
[22] Shukla A, Hassan-Laskar N, Ahmad-Riziv I. (2016). Design of shell \& tube heat exchanger. International Journal of Research in Aeronautical and Mechanical Engineering 4(1): 1-23.

[23] Mohanraj M, Jayaraj S, Muraleedharan C. (2015). Applications of artificial neural networks for thermal analysis of heat exchangers - A review. International Journal of Thermal Sciences 90: 150-172. https://doi.org/10.1016/j.ijthermalsci.2014.11.030

[24] Chandra-Sekhar B, Krishnaiah D, Anand-Raju F. (2014). Thermal analysis of multi tube pass shell and tube heat exchanger. International Journal of Innovative Research in Science, Engenieering and Technology 3(11): $\quad$ 17605-17612. https://doi.org/10.15680/IJIRSET.2014.0311071

[25] Sarma PK, Konijeti R, Subramanyam T, Prasad L, Korada VS, Srinivas V, Vedula DR, Prasad V. (2017). Fouling and its effect on the thermal performance of heat exchanger tubes. International Journal of Heat and Technology 35(3): https://doi.org/10.18280/ijht.350307

[26] Ogbonnaya SK, Ajayi OO. (2017). Fouling phenomenon and its effect on heat exchanger: A review. Frontiers in Heat and Mass Transfer 9(31): 1-12. https://doi.org/10.5098/hmt.9.31

[27] Li Q, Liu C, Zhang Z. (2014). Prediction of solubility of sulfur in hydrogen sulfide based on molecular dynamics simulation. Asian Journal of Chemistry 26(4): 10411043. https://doi.org/10.14233/ajchem.2014.15843

\section{NOMENCLATURE}

$a, b, c$
$A$
$C$
$C_{m \text { 韓 }}$
$C p$
$d_{e}$
$d_{i}$

coefficients of the ODE system

heat transfer area, $\mathrm{m}^{2}$

stream heat capacity, $\mathrm{J} /(\mathrm{s} \cdot \mathrm{K})$

minimum heat capacity, $\mathrm{J} /(\mathrm{s} \cdot \mathrm{K})$

specific heat at constant pressure, $\mathrm{J} /(\mathrm{kg} \cdot \mathrm{K})$

tube outside diameter, $\mathrm{m}$

tube inside diameter, $\mathrm{m}$

$\begin{array}{ll}D_{e} & \text { shell outside diameter, } \mathrm{m} \\ D_{i} & \text { shell inside diameter, } \mathrm{m} \\ F & \text { LMTD correction factor } \\ G_{1} \ldots G_{4} & \text { constants of the ODE system } \\ h & \text { convective heat transfer coefficient, } \\ k_{m} & \mathrm{~W} /\left(\mathrm{m}^{2} \cdot \mathrm{K}\right) \\ \dot{m} & \text { thermal conductivity of metal, } \mathrm{W} /(\mathrm{m} \cdot \mathrm{K}) \\ P & \text { fluid mass flowrate, } \mathrm{kg} / \mathrm{s} \\ Q & \text { heat transfer surface perimeter, } \mathrm{m} \\ r_{1}, r_{2} & \text { heat transfer rate, } \mathrm{W} \\ R & \text { roots of the ODE system } \\ R_{f} & \text { heat capacity rate ratio } \\ S & \text { fouling thermal resistance, } \mathrm{m}^{2} \cdot \mathrm{K} / \mathrm{W} \\ t & \text { temperature effectiveness } \\ T & \text { elapsed time in operations, } \mathrm{h} \\ \Delta T & \text { temperature, } \mathrm{K} \\ \Delta T_{m l} & \text { temperature difference, } \mathrm{K} \\ U & \text { logarithmic mean temperature difference, } \mathrm{K} \\ x & \text { overall heat transfer coefficient, } \mathrm{W} /\left(\mathrm{m}{ }^{2} \cdot \mathrm{K}\right) \\ & \text { axial position over the heat exchanger } \\ \text { length, } \mathrm{m}\end{array}$

\section{Greek symbols}

$\varepsilon \quad$ heat exchanger efficiency, $\%$

\section{Subscripts}

1 heat exchanger inlet conditions

2 heat exchanger outlet conditions

a tubeside fluid

abs absorbed

$b \quad$ shellside fluid

$c \quad$ jacket-side fluid

$e \quad$ external heat exchange

$i \quad$ internal heat exchange

rel released 